\title{
LA FUNDAMENTACIÓN DE LAS SENTENCIAS Y LA SANA CRÍTICA
}

\author{
Joel González Castillo*
}

\begin{abstract}
RESUMEN: Pronto en Chile la prueba legal o tasada dejará de ser el régimen general de valoración de la prueba ocupando su lugar el sistema de la sana crítica. Más que nunca interesa, por tanto, determinar qué es verdaderamente la sana crítica, cuáles son sus elementos esenciales, sus límites y en especial su vinculación con el deber de los tribunales de fundamentar o motivar adecuadamente sus sentencias. Se analiza el tratamiento doctrinal, jurisprudencial y legislativo de la sana crítica. Y finalmente se hace un análisis crítico de la forma en que los jueces han hecho uso de esta herramienta.
\end{abstract}

Palabras clave: Sana crítica, prueba, fundamentación de sentencias, razonamiento judicial, Derecho Procesal.

ABSTRACT: The so-called system of legal or "assessed" evidence (prueba legal o tasada) is soon to be abandoned in Chilean law. It is to be replaced by the so-called system of "sane criticism" (sana critica), i.e. a judge-based assessment of the value of the evidence brought up in a particular trial. It is therefore more urgent than ever to determine what the sana critica really is, which are its key elements, its limits and, most importantly, its relationship with the duty of the judges to ground o provide their sentences with enough motives. This article analyzes how the scholars, the caselaw and the law deal with this tool. Finally, it criticizes the way the judges have been using the sana critica.

Key words: Sana crítica, evidence, grounding sentences, legal reasoning, procedure.

\section{INTRODUCCIÓN}

Muchos textos legales nuevos, sin perjuicio de algunos antiguos, están confiriendo a los tribunales la facultad de apreciar la prueba de acuerdo a las reglas de la sana crítica. Solo a modo de ejemplo, pueden citarse las siguientes materias en que ella se aplica: asuntos de conocimiento de los nuevos tribunales de familia (Ley $\mathrm{N}^{\circ} 19.968$, art. 32); nuevo proceso penal (Código Procesal Penal, art. 297); medio ambiente (Ley No 19.300, art. 62); protección de los derechos de los consumidores (Ley No 19.496, art. 56 , hoy art. $50 \mathrm{~B}$, con la reforma de la Ley $\mathrm{N}^{\circ} 1$ 19.955); copropiedad inmobiliaria (Ley No 19.537, art. 33); protección de los derechos de propiedad industrial (Ley No 19.039, arts. 16 y 111, modificados e incorporados, respectivamente, por la Ley $\mathrm{N}^{\circ} 19.996$ ); defensa de la libre competencia (Decreto Ley $\mathrm{N}^{\circ} 211$, art. 22, inciso final); Recurso de Protección (Auto Acordado de la Corte Suprema sobre tramitación de dicho recurso, No 5); procedimiento ante los juzgados de policía local (Ley $\mathrm{N}^{\circ} 18.287$, art. 14); juicios laborales (Código del Trabajo, arts. 455 y 459 letra d); regularización de la posesión de

\footnotetext{
*Abogado, Profesor de Derecho Civil, Pontificia Universidad Católica de Chile.
} 
la pequeña propiedad raíz (D.L. No 2.695, art. 22); arrendamiento de predios urbanos (Ley $\mathrm{N}^{\circ} 18.101$, art. 15, hoy art. $8 \mathrm{~N}^{\circ} 7$, con la reforma de la Ley $\mathrm{N}^{\circ} 19.866$ ); juicios de alimentos (Ley $\mathrm{N}^{\circ} 14.908$, art. $1^{\circ}$ inc. $2^{\circ}$ ); informes de peritos (Código de Procedimiento Civil, art. 425); etc.

Sin embargo, lo más importante es que la tradicional enseñanza en cuanto a que la prueba legal o tasada era el régimen general de valoración de la prueba muy pronto dejará de serlo. En efecto, las comisiones que están trabajando en la redacción de un nuevo Código Procesal Civil proponen la sana crítica como regla general en todos los juicios civiles ${ }^{1}$.

Como se aprecia, el legislador está apostando en firme por la prevalencia de la sana crítica como sistema de valoración de la prueba. Son amplísimas y de la más variada índole las materias en que el legislador se ha inclinado por este mecanismo. La tendencia legislativa pareciera ser la de ampliar las atribuciones del juez en la apreciación de la prueba. ¿Estará reflejando esto una mayor confianza hacia nuestros jueces? La pregunta es válida pues nadie puede desconocer que frente al sistema de la prueba legal o tasada, el sistema de la sana crítica o persuasión racional implica necesariamente darle una mayor libertad al tribunal en la valoración de la prueba, pero también una mayor responsabilidad y confianza. Más que la expresión de una "moda" en el pensamiento político procesal la sana crítica refleja una necesidad de superar las rigideces de la prueba tasada, sistema este último cuyas causas pueden ser varias, pero como afirma Cabañas García "todas finalmente se reconducen a dos: el deseo de una certidumbre invariada en el resultado de la resolución de ciertas materias litigiosas; y, no en menor grado, una evidente desconfianza hacia la figura del juez, cuya actuación pretende enervarse por este conducto" 2 .

La actividad de valoración, que duda cabe, es una de las áreas más intrincadas y movedizas dentro del vasto mundo probatorio, y acaso también la de más penoso transitar debido a la gran cantidad de elementos metajurídicos, por añadidura inestables, que la rodean.

${ }^{1}$ Vid Departamento de Derecho Procesal de la Pontificia Universidad Católica de Chile (2005), pp. 110 y 131; Comisión para la Reforma del Proceso Civil, Facultad de Derecho de la Universidad de Chile (2005) p. 48. Eso sí, ambos informes hacen salvedad de la prueba instrumental. Se lee en el primero: "Es el caso de los instrumentos, que debieran continuar rigiéndose por las normas vigentes. Lo mismo cabría aplicar a las presunciones, cuya exigencia de ser graves, precisas y concordantes, tampoco debiera desaparecer"; en tanto en similares términos dice el segundo: "La única excepción en esta materia sería los instrumentos públicos, en especial, el caso de las escrituras publicas en los actos en que constituyen solemnidad, dado que el contrato solemne se prueba por su solemnidad". Si finalmente se acepta la sana crítica como sistema general de apreciación de la prueba un tema que habrá que abordar es la procedencia del recurso de casación en el fondo cuando una sentencia haya sido dictada con infracción a las reglas de la sana crítica. Hasta ahora, nuestra Corte Suprema considera, por regla general, que los elementos integrantes de la sana crítica no son normas reguladoras de la prueba, sino que se trata de cuestiones de hecho, cuya apreciación es privativa de los jueces de fondo y por lo mismo no susceptibles de casación en el fondo. Sin embargo en alguna ocasión, el máximo tribunal ha sostenido que las reglas de la sana crítica sí constituirían normas reguladoras de la prueba: "La ponderación de los elementos de convicción allegados a la causa y el subsecuente establecimiento de los hechos no admite revisión vía recurso de Casación, salvo que se hayan infringido las normas de la sana crítica...". Aravena con Biobío Comunicaciones S.A. (2002).

2 CABAÑAS (1992) p. 70. Una argumentada defensa de la prueba tasada pude verse en JimÉNEZ (1978) pp. 54-62. 


\section{LA SANA CRÍTICA SEGÚN LA DOCTRINA ${ }^{3}$}

Hugo Alsina dice que "Las reglas de la sana crítica, no son otras que las que prescribe la lógica y derivan de la experiencia, las primeras con carácter permanente y las segundas, variables en el tiempo y en el espacio"'.

Por su parte Couture define las reglas de la sana critica como "las reglas del correcto entendimiento humano; contingentes y variables con relación a la experiencia del tiempo y del lugar; pero estables y permanentes en cuanto a los principios lógicos en que debe apoyarse la sentencia" 5 .

Explayándose en el tema nos enseña que las reglas de la sana crítica configuran una categoría intermedia entre la prueba legal y la libre convicción. Sin la excesiva rigidez de la primera y sin la excesiva incertidumbre de la última, configura una feliz fórmula de regular la actividad intelectual del juez frente a la prueba. Las reglas de la sana crítica son, para él ante todo, "las reglas del correcto entendimiento humano. En ellas interfieren las reglas de la lógica, con las reglas de la experiencia del juez. Unas y otras contribuyen de igual manera a que el magistrado pueda analizar la prueba con arreglo a la sana razón y a un conocimiento experimental de los casos. El juez que debe decidir con arreglo a la sana crítica, no es libre de razonar a voluntad, discrecionalmente, arbitrariamente. Esta manera de actuar no sería sana crítica, sino libre convicción. La sana crítica es la unión de la lógica y la experiencia sin excesivas abstracciones de orden intelectual, pero también sin olvidar esos preceptos que los filósofos llaman de higiene mental, tendientes a asegurar el más certero y eficaz razonamiento".

\footnotetext{
${ }^{3}$ Atendido que para la gran mayoría de la doctrina y la jurisprudencia son términos similares prescindiremos de las discusiones en torno a si "valorar" y "apreciar" la prueba son o no sinónimos, como si igualmente lo son las expresiones "sana crítica" y "valorar en conciencia". Además, en el caso de nuestra legislación nacional mucho de esta discusión ha perdido vigencia desde que prácticamente todas las leyes citadas al comienzo de este trabajo y que hacían referencia a la apreciación de la prueba "en conciencia", ahora -aprovechando reformas que se les han introducido- hablan de sana crítica. Sobre el particular véase SALAS (1993) pp. 117 125. Lo que sí es diferente es "fallar en conciencia". En efecto, no hay que confundir la apreciación de la prueba en conciencia o de acuerdo a las reglas de la sana crítica y la facultad de fallar en conciencia que denota un concepto distinto, como es el de resolver la litis no ateniéndose a las leyes de derecho positivo, sino a la propia convicción que el juez se haya formado tomando en cuenta las circunstancias de la especie. En tal caso el juez queda relevado de todas las normas reguladoras de la prueba, no solo de las de valoración. Es más, queda relevado de todo el Derecho sustantivo. Vid Peñailillo (1993) p. 93; Vodanovic H. (1994) p. 253. En una sentencia de 19 de julio de 1954, la Corte Suprema declara que, atendiendo a los significados que da a las palabras el Diccionario de la Lengua, fallar en conciencia es fallar con conocimiento exacto y reflexivo de las cosas, fallar según lo que le dicta al juez su propio entendimiento, fallar de acuerdo con la equidad, más por el sentimiento del deber y de la conciencia, que por el perentorio texto de la ley $(R$. de Ciencias Penales, 1956 , t. 15, № 2, p. 59, cons. $7^{\circ}$ ). Casos específicos en que se ha permitido expresamente a los tribunales fallar en conciencia eran el art. 18 letra k) del D.L. 211, sobre defensa de libre competencia, que facultaba a la Comisión Resolutiva para apreciar la prueba en conciencia, pero además para fallar del mismo modo y los arts. 27 letra j) de la Ley de Seguridad del Estado y $7^{\circ}$ inciso final de la Ley No 16.455 de 6 de abril de 1966, llamada de Inamovilidad del Empleo, que autorizaban a apreciar la prueba y fallar en conciencia. Hernán Zapata analizando esta última disposición concluye que ella introdujo el sistema de prueba libre o de libre convicción, ZAPATA p. 53.
}

${ }^{4}$ Alsina (1956) p. 127.

5 Couture (1979) p. 195. 
Couture destaca la diferencia entre la sana crítica y la libre convicción pues este último es "aquel modo de razonar que no se apoya necesariamente en la prueba que el proceso exhibe al juez, ni en medios de información que pueden ser fiscalizado por las partes. Dentro de este método el magistrado adquiere el convencimiento de la verdad con la prueba de autos, fuera de la prueba de autos y aun contra la prueba de autos". El juez -continúano está obligado a apoyarse en hechos probados, sino también en circunstancias que le consten aun por su saber privado; y "no es menester, tampoco, que la construcción lógica sea perfecta y susceptible de ser controlada a posteriori; basta en esos casos con que el magistrado afirme que tiene la convicción moral de que los hechos han ocurrido de tal manera, sin que se vea en la necesidad de desarrollar lógicamente las razones que le conducen a la conclusión establecida" 6 .

Respecto de la relación entre la sana crítica y la lógica, Couture hace ver que las reglas de la sana crítica consisten en su sentido formal en una operación lógica. Existen algunos principios de lógica que no podrán ser nunca desoídos por el juez. Así, dice, nadie dudaría del error lógico de una sentencia en la cual se razonara de la siguiente manera: los testigos declaran que presenciaron un préstamo en monedas de oro; como las monedas de oro son iguales a las monedas de plata, condeno a devolver monedas de plata. Evidentemente, está infringido el principio lógico de identidad, según el cual una cosa solo es igual a sí misma. Las monedas de oro solo son iguales a las monedas de oro, y no a las monedas de plata. De la misma manera, habría error lógico en la sentencia que quebrantara el principio del tercero excluido, de falta de razón suficiente o el de contradicción. Pero -agrega- es evidente que la corrección lógica no basta para convalidar la sentencia. La elaboración del juez puede ser correcta en su sentido lógico formal y la sentencia ser errónea. Por ejemplo, un fallo razona de la siguiente manera: todos los testigos de este pueblo son mentirosos; este testigo es de este pueblo; en consecuencia, ha dicho la verdad. El error lógico es manifiesto, pero desde el punto de vista jurídico la solución puede ser justa si el testigo realmente ha dicho la verdad. Pero puede ocurrir otra suposición inversa. Dice el juez: todos los testigos de este pueblo son mentirosos; este testigo es de este pueblo; en consecuencia es mentiroso. En este último supuesto los principios lógicos han sido respetados ya que el desenvolvimiento del silogismo ha sido correcto. Pero la sentencia sería injusta si hubiera fallado una de las premisas: si todos los hombres del pueblo no fueran mentirosos, o si el testigo no fuera hombre de ese pueblo.

Igual importancia asigna a los principios de la lógica y a las reglas de la experiencia en la tarea de valoración de la prueba ya que el juez no es una máquina de razonar, sino, esencialmente, un hombre que toma conocimiento del mundo que le rodea y le conoce a través de sus procesos sensibles e intelectuales. La sana crítica es, además de lógica, la correcta apreciación de ciertas proposiciones de experiencia de que todo hombre se sirve en la vida. Esas conclusiones no tienen la estrictez de los principios lógicos

\footnotetext{
${ }^{6}$ La doctrina en general está conteste en que la libre convicción permite al juez formar su convencimiento con absoluta libertad y, lo más importante, sin tener que dar razones acerca de cómo adquirió dicho convencimiento, esto es justamente lo que la diferencia de la sana crítica.
} 
tradicionales, sino que son contingentes y variables con relación al tiempo y al lugar. El progreso de la ciencia está hecho de una serie de máximas de experiencia derogadas por otras más exactas; y aun frente a los principios de la lógica tradicional, la lógica moderna muestra cómo el pensamiento humano se halla en constante progreso en la manera de razonar. Lo anterior lo lleva a concluir que es necesario considerar en la valoración de la prueba el carácter forzosamente variable de la experiencia humana, tanto como la necesidad de mantener con el rigor posible los principios de lógica en que el derecho se apoya ${ }^{7}$. Las llamadas máximas de experiencia Couture las define como "normas de valor general, independientes del caso especifico, pero como se extraen de la observación de lo que generalmente ocurre en numerosos casos, son susceptibles de aplicación en todos los otros casos de la misma especie" ${ }^{8}$.

Para Friedrich Stein, a quien se debe la introducción en el derecho procesal del concepto máximas de experiencia, estas "son definiciones o juicios hipotéticos de contenido general, desligados de los hechos concretos que se juzgan en el proceso, procedentes de la experiencia, pero independientes de los casos particulares de cuya observación se han inducido y que, por encima de esos casos, pretenden tener validez para otros nuevos" 9 .

Calamandrei, por su parte, las define como aquellas "...extraidas de su patrimonio intelectual (del juez) y de la conciencia pública...” y destaca su utilidad pues "las máximas de experiencia poseidas por él, por lo general, le servirán de premisa mayor para sus silogismos (por ejemplo, la máxima de que la edad avanzada produce en general un debilitamiento de la memoria, le hará considerar en concreto la deposición de un testigo viejo menos digna de crédito que la de un testigo todavía joven)..."10.

Empero, cualquiera que sea el concepto que se dé sobre las máximas de la experiencia, es posible encontrar ciertos elementos que les son comunes y tales son, según un autor los siguientes: $1^{\circ}$ Son juicios, esto es, valoraciones que no están referidas a los hechos que son materia del proceso, sino que poseen un contenido general. Tienen un valor propio e independiente, lo que permite darle a la valoración un carácter lógico; $2^{\circ}$ Estos juicios tienen vida propia, se generan de hechos particulares y reiterativos, se nutren de la vida en sociedad, aflorando por el proceso inductivo del juez que los aplica; $3^{\circ}$ No nacen ni fenecen con los hechos, sino que se prolongan más allá de los mismos, y van a tener validez para otros nuevos; $4^{\circ}$ Son razones inductivas acreditadas en la regularidad o normalidad de la vida, y, por lo mismo, implican una regla, susceptible de ser utilizada por el juez para un hecho similar; $5^{\circ}$ Las máximas carecen de universalidad. Están restringidas al medio físico en que actúa el juez, puesto que ellas nacen de las relaciones de la vida y comprenden todo lo que el juez tenga como experiencia propia ${ }^{11}$.

\footnotetext{
7 Couture (1966) pp. 270-274.

${ }^{8}$ Couture (1966) p. 192.

${ }^{9}$ STEIN (1988) p. 27.

10 Calamandrei (1961) p. 381.

11 Vid Oberg (1985) p. 54. Por su especialidad, además, sugerimos al lector el artículo de Carnelli (1946) pp. $125-150$.
} 
Digamos, finalmente, que por sus propias características a las máximas de experiencia no les rige la prohibición común de no admitir otros hechos que los probados en el juicio. La máxima quod non est in actis non est in mundo no es aplicable totalmente a ellas ya que implicaría rechazar juicios o razones que por su generalidad, notoriedad, reiteración y permanencia en el tiempo se tienen generalmente por aceptados por la sociedad.

\section{LA SANA CRÍTICA SEGÚN LA JURISPRUDENCIA}

Nuestros tribunales se han pronunciado en forma bastante uniforme sobre qué debe entenderse por sana crítica. Así, han sostenido: "Que, según la doctrina, la 'sana crítica, es aquella que nos conduce al descubrimiento de la verdad por los medios que aconseja la razón y el criterio racional, puesto en juicio. De acuerdo con su acepción gramatical puede decirse que es el analizar sinceramente y sin malicia las opiniones expuestas acerca de cualquier asunto"12.

Otra sentencia dijo: "Que en conciencia, significa, según el Diccionario de la Lengua Española, arreglado a la conciencia, es decir, con arreglo al conocimiento interior del bien que debemos hacer y del mal que debemos evitar, términos que en el lenguaje vulgar significan lo mismo; pues cuando se apela a la conciencia de una persona o se le dice que proceda en conciencia, se invoca un noble sentimiento que se ejerce para hacer el bien y para evitar el mal, que es el primer principio de moral;... Que en manera alguna la ley ha querido, con entregar la apreciación de las pruebas a la conciencia, dejarlas al azar, al capricho o a la arbitrariedad. El concepto de la conciencia no es nuevo en las leyes y siempre ha tenido la acepción de una regla de bondad y de justicia y no de maldad o abuso... Cuando la ley habla de que se proceda discrecionalmente o con prudente criterio, tampoco abre las puertas al desorden y a la licencia, ni se hacía esto conforme a las viejas fórmulas 'según su leal saber y entender' o 'a verdad sabida y buena fe guardada', que siempre han impulsado a tener la voluntad firme y constante de dar a cada uno lo que le pertenece"13.

En resumen "...en el sistema de la sana crítica, el tribunal debe asesorarse por sus conocimientos técnicos, su experiencia personal, la lógica, el sentido común, el buen juicio, y la recta intención"14.

\section{LA SANA CRÍTICA SEGÚN LA LEGISLACIÓN}

Además de los autores y de los tribunales, también el legislador se ha pronunciado sobre lo que es la sana crítica. Concretamente lo ha hecho en dos artículos de idéntica redacción: el inciso $2^{\circ}$ del art. 14 de la Ley 18.287 que establece procedimiento ante los juzgados de policía local y el art. 456 del Código del Trabajo, que rezan: "Al apreciar la prueba de acuerdo con las reglas de la sana critica, el tribunal deberá expresar las razones

\footnotetext{
12 Budinich con Cerda (1996) p. 76.

${ }^{13}$ Cía Salitrera Anglo Chilena (1933) pp. 502-503.

${ }^{14}$ Peretta con Simunovic (1971) p. 66.
} 
jurídicas y las simplemente lógicas, cientificas o técnicas en cuya virtud les asigne valor o las desestime. En general, tomará en especial consideración la multiplicidad, gravedad, precisión, concordancia y conexión de las pruebas y antecedentes del proceso que utilice, de manera que el examen conduzca lógicamente a la conclusión que convence al sentenciador".

Dichas disposiciones eran hasta hace muy poco las únicas que regulaban la sana crítica, situación que cambió con la Ley $\mathrm{N}^{\circ} 19.968$ sobre nuevos tribunales de familia cuyo art. 32 también se refiere a ella en los siguientes términos: "Valoración de la prueba. Los jueces apreciarán la prueba de acuerdo a las reglas de la sana crítica. En consecuencia, no podrán contradecir los principios de la lógica, las máximas de la experiencia y los conocimientos cientificamente afianzados. La sentencia deberá hacerse cargo en su fundamentación de toda la prueba rendida, incluso de aquella que hubiere desestimado, indicando en tal caso las razones tenidas en cuenta para hacerlo. La valoración de la prueba en la sentencia requerirá el señalamiento de los medios de prueba mediante los cuales se dieren por acreditados cada uno de los hechos, de modo de contener el razonamiento utilizado para alcanzar las conclusiones a que llegare la sentencia". Igual redacción tiene el artículo 297 del nuevo Código Procesal Penal, solo que comienza así: "Valoración de la prueba. Los tribunales apreciarán la prueba con libertad, pero no podrán contradecir los principios de la lógica...”.

Un par de comentarios sobre estos dos últimos artículos. En primer lugar, se observa que ambos incorporan, además de los dos elementos clásicos de la sana crítica -principios de la lógica y máximas de la experiencia-, "los conocimientos científicamente afianzados". Y en segundo lugar, el Código Procesal Penal habla que los jueces apreciarán la prueba "con libertad" con lo que pudiera pensarse que en este caso el legislador se quiso apartar de la sana crítica, pero la verdad es que a continuación el propio artículo se encarga de aclarar que ello no es así, pues dice que dicha facultad de los tribunales no pueden contradecir "los principios de la lógica, las máximas de la experiencia y los conocimientos científicamente afianzados" elementos que sin discusión caracterizan por definición el sistema de la sana crítica.

\section{A MODO DE RESUMEN: CARACTERES DISTINTIVOS DE LA SANA CRÍTICA}

De lo afirmado por la doctrina, jurisprudencia y normas legales sobre la sana crítica podemos extraer varias cosas.

Lo primero es que el sistema de la sana crítica solo se refiere a la "valoración de la prueba", luego es claro que esa fórmula legal mantiene subsistentes, vigentes, en la respectiva materia, las demás normas sustantivas probatorias, denominadas reglas reguladoras de la prueba como las que señalan cuáles son los medios de prueba, las que establecen su admisibilidad, la forma de rendir la prueba o las que distribuyen el peso de ella. Disponiendo la ley que el juez apreciará la prueba en conciencia, debe este, sin embargo, respetar estas otras normas reguladoras que nada tienen que ver con su apreciación ${ }^{15}$.

15 Sobre esto véase PeÑAILILlo (1993) pp. 19, 92. Vodanovic (1994) p. 253. RioseCO (1995) p. 248. 
En segundo lugar el concepto mismo de sana crítica se ha ido decantando sustancialmente a través del tiempo, no habiendo hoy en día prácticamente discusión en cuanto a que son dos fundamentalmente los elementos que la componen: i) la lógica con sus principios de identidad (una cosa solo puede ser igual a sí misma); de contradicción (una cosa no puede ser explicada por dos proposiciones contrarias entre sí); de razón suficiente (las cosas existen y son conocidas por una causa capaz de justificar su existencia); del tercero excluido (si una cosa únicamente puede ser explicada dentro de una de dos proposiciones alternativas, su causa no puede residir en una tercera proposición ajena a las dos precedentes) y ii) las máximas de experiencia o "reglas de la vida", a las que el juzgador consciente o inconscientemente recurre, ya tratadas. A ello agregaríamos iii) los conocimientos cientificamente afianzados (según exigen los preceptos legales nacionales citados), y iv) la obligación de fundamentar la sentencia, rasgo que distingue a este sistema de la libre ó íntima convicción, que luego analizaremos.

De manera que el juez llamado a valorar la prueba en conciencia no tiene libertad para valorar, sino que debe atenerse en su labor de sentenciador necesariamente, por lo menos, a los dos primeros referentes. Si no los respeta se abre paso a la arbitrariedad judicial y a la incertidumbre de las partes que son las principales objeciones a este sistema de la sana crítica. En efecto se dice que existe "peligro de la arbitrariedad, de que no puede preverse el resultado del proceso ni tenerse una seguridad probatoria, y de que una incógnita (la sentencia) queda dependiendo de otra incógnita (la convicción intima)"16, y lleva la incertidumbre a las partes que intervienen en el proceso; pues, con el sistema tarifario, cada parte conocerá de antemano el valor de la prueba que va a aportar al proceso.

Otro aspecto relevante es que lo que informa o inspira la sana crítica es la racionalidad. La apreciación o persuasión en este sistema debe ser racional, lo que la diferencia totalmente del convencimiento que resulta del sentimentalismo, de la emotividad, de la impresión. Los razonamientos que haga el juez deben encadenarse de tal manera que conduzcan sin violencia, "sin salto brusco", a la conclusión establecida y sus juicios deben ser susceptibles de confrontación con las normas de la razón.

\section{LA FUNDAMENTACIÓN DE LAS SENTENCIAS}

De acuerdo al Diccionario de la Real Academia Española fundar, en su acepción quinta, significa "Apoyar con motivo y razones eficaces o con discursos una cosa".

Couture al definir "Fundamentos de la sentencia" dice: "Conjunto de motivos, razones o argumentos de hecho y especialmente de derecho en que se apoya una decisión judicial"17.

El que los fallos deban ser fundados no es solo una exigencia legal (art. 170 Nos 4 y 5 del Código de Procedimiento Civil y Nos 5 a 10 del Auto Acordado de la Corte Suprema sobre la forma de las sentencias) sino, además, como muy bien lo ha observado

${ }^{16}$ DeVIS (1972) p. 105.

17 COUTURe (1960) p. 311. 
don Juan Guzmán Tapia “...es un imperativo constitucional. Hay constituciones de varios estados, cual es el caso de la española y la peruana, que consagran expresamente la obligación de los jueces de fundamentar o motivar sus sentencias. La Constitución española en su artículo $120 \mathrm{~N}^{\circ} 3^{\circ}$ establece: 'Las sentencias serán siempre motivadas y se pronunciarán en audiencia pública'. La Constitución Política del Perú, de 1993, por su parte, dispone en su artículo 139: 'Son principios y derechos de la función jurisdiccional:... No 5. La motivación escrita de las resoluciones judiciales en todas las instancias, excepto los decretos de mero trámite, con mención expresa de la ley aplicable y de los fundamentos de hecho en que se sustenten".

El ex magistrado sostiene que en el caso de nuestro país de los artículos $19 \mathrm{~N}^{\circ} 3^{\circ}$, inciso $5^{\circ}$ (garantías de un racional y justo procedimiento) y 73 de la Constitución (prohibición de revisar los fundamentos o contenidos de las resoluciones) se deduce la clara voluntad del constituyente en cuanto a elevar a nivel constitucional la obligación de los jueces de fundamentar sus fallos. Por su parte, la normativa legal contenida en los artículos 170 y $768 \mathrm{~N}^{\circ} 5^{\circ}$ del Código de Procedimiento Civil; 500 y $541 \mathrm{~N}^{\circ} 9^{\circ}$ del Código de Procedimiento Penal, a la cual obviamente hace referencia nuestra Carta Fundamental, resulta explícita en cuanto a la imperatividad de la fundamentación o motivación de los fallos ${ }^{18}$.

También para don Hugo Pereira Anabalón y don José Luis Cea es un imperativo constitucional del ejercicio de la jurisdicción el que las resoluciones sean fundadas. Para el último ello es una de las manifestaciones del debido proceso y agrega "...la fundamentación de las sentencias en la legalidad positiva vigente o, subsidiariamente, en el espiritu general de la legislación o en la equidad natural (...) figura consagrada sobre todo en el Art. 73 inciso $2^{\circ}$ de la Carta, el Art. 24 del Código Civil, el Art. 10 inciso $2^{\circ}$ del COT y los Arts. 160, 170 y 785 del CPC, reglamentados en el Auto Acordado dictado por la Corte Suprema el 30 de Septiembre de 1920 "19.

En la misma línea de argumentación Hugo Pereira sostiene: "La declaración del derecho la hacen los jueces en la sentencia, acto integrante del procedimiento 'racional' requerido por el Constituyente, racionalidad que impone cierta exigencia que el pueblo 'siente' como un bien o un valor: la fundamentación o motivación de la misma". Citando al catedrático español don Manuel Ortells Ramos dice que este sintetiza de la siguiente manera la necesidad de fundamentar las sentencias: "10 La motivación exige referirse a la ley de la cual se hace aplicación, impidiendo que la decisión se funde en el arbitrio judicial, originador de la inseguridad juridica de los ciudadanos; $2^{\circ}$ La motivación favorece una mayor perfección en el proceso interno de elaboración de la sentencia; $3^{\circ}$ Ella cumple una función persuasiva o didáctica; $4^{\circ}$ La motivación facilita la labor de los órganos jurisdiccionales que conocen de las impugnaciones de la sentencia" 20.

\footnotetext{
18 Cfr. GUZMÁN (1996) pp. 92-94.

${ }^{19}$ CEA (1988) p. 309.

${ }^{20}$ Pereira (1992) pp. 11, 13.
} 
En el marco de los principios fundamentales del procedimiento es indispensable que los jueces expliquen y fundamenten sus decisiones, a menos que se trate de simples órdenes para el impulso del proceso; así "se evitan arbitrariedades y se permite a las partes usar adecuadamente el derecho de impugnación contra la sentencia para los efectos de la segunda instancia, planteándole al superior las razones legales y jurídicas que desvirtúan los errores que condujeron al juez a su decisión. Porque la resolución de toda sentencia es el resultado de las razones o motivaciones que en ella se explican" 21.

Como se puede ver todos los autores insisten en la idea de que lo que se trata de evitar esencialmente con la fundamentación -o motivación como también se habla- de las sentencias es la arbitrariedad ${ }^{22}$ que, de acuerdo al Diccionario de la Real Academia Española, significa "Acto o proceder contrario a la justicia, la razón o las leyes, dictado solo por la voluntad o el capricho".

\section{LA SANA CRÍTICA EXIGE LA FUNDAMENTACIÓN DE LAS SENTENCIAS}

El deber de fundamentación rige para las sentencias en general, sean o no dictadas en asuntos en que se faculta al juez a apreciar la prueba en conciencia. Así acertadamente lo ha entendido la jurisprudencia. Un fallo de la Corte Suprema ha dicho "La apreciación de la prueba en conciencia no autoriza a hacer simples estimaciones, por cuanto la conciencia debe formarse de conformidad con las normas que establecen la lógica y las leyes para dar conocimiento exacto y reflexivo de las cosas, y la sentencia debe explicar las normas a que se sujeta para dar la razón de su final veredicto" ${ }^{23}$. Otros fallos apuntan en la misma dirección de la necesidad de fundamentar: "...el fallo en conciencia no significa autorizar la arbitrariedad (del árbitro arbitrador), ni permitir las afirmaciones sin fundamentos, para resolver la contienda" 24; "Que esta apreciación (en conciencia) no importa la facultad o autorización para que los jueces se limiten a hacer una enumeración de los elementos de juicio que sirvan de base para arribar a una determinada conclusión ni tampoco para hacer una arbitraria estimación. $8^{\circ}$ Que, en efecto, resolver en conciencia un negocio es decidir con conocimiento exacto y reflexivo, o sea con conocimiento fiel y cabal de la cuestión propuesta..." 25; "Que la facultad otorgada a los tribunales para apreciar la prueba en conciencia, no los exonera del estudio detenido y acucioso de la prueba rendida y solo una vez hecho esto puede recurrir a su conciencia para dictar decisión" 26 .

La doctrina participa del criterio jurisprudencial anterior. Don Juan Colombo sostiene que el juez que no expresa lo que su conciencia le indica en la sentencia, excede al sistema de valoración en conciencia para traspasarse al sistema de la libre convicción que obviamente no es el que señala nuestra ley. Representa peligros que el legislador

\footnotetext{
${ }^{21}$ DeVIS (1966) p. 66.

${ }^{22}$ Cfr. GuZMÁn (1996) p. 82; Stoehrel (1995), p. 102; Rodríguez (1993) p. 500.

${ }^{23}$ Muñoz con Corte de Apelaciones Valparaíso (1952) p. 41, cons. 1º

${ }^{24}$ Duque Wenceslao (1972) p. 131.

25 Contra Garacino, José (1960) p. 41

26 Infante y otro con Jury (1980) p. 447.
} 
tuvo claros cuando se salió de la prueba tasada para darle mayor flexibilidad al juez "pero esta flexibilidad tiene que tener un límite y él consiste en la obligación que el juez tiene de convencer de alguna manera de la justicia de su decisión de los demás" 27.

Como bien dice Alcalá-Zamora y Castillo la sana crítica "debe exteriorizar un juicio razonado que indique por qué motivos se acepta o rechaza, en todo o en parte, una opinión expuesta, mas sin que oscile de la sumisión ciega a la desconfianza infundada" 28.

En palabras de otro autor la verdad jurídica pende en este sistema, no de la impresión, sino de la conciencia del juez, que no puede juzgar simplemente, según su criterio individual, sino según las reglas de la verdad histórica, que debe fundamentar. El convencimiento del juez debe responder a su conciencia, pero, no a una conciencia que juzga por impresión, sino que juzga a razón vista y por motivos lógicos ${ }^{29}$.

En el régimen de la sana crítica o persuasión racional "el juez debe dar los motivos por los que adquiere su convicción, lo que es una importante garantía para asegurar que resolverá la litis según allegata et probata, pues, al tener que ponderar la prueba y dar las razones de su convencimiento, necesariamente tiene que apreciar en mejor forma los datos probatorios". "No le es permitido (al juez) obrar prima facie, sin formarse una entera convicción, sino que, por el contrario, debe llegar a un pleno conocimiento del facta probandi a través de un estudio razonado de la prueba, pues la sentencia no puede apoyarse en un juicio dubitable, sino en hechos realmente demostrados en el juicio" 30 .

En el mismo sentido opina Juan Montero Aroca para quien las reglas de la sana crítica son máximas de las experiencias judiciales, en el sentido de que se trata de máximas que deben integrar la experiencia de la vida del juez y que este debe aplicar a la hora de determinar el valor probatorio de cada una de las fuentes-medios de prueba. Y en la parte que ahora nos importa señala: "Esas máximas no pueden estar codificadas, pero si han de hacerse constar en la motivación de la sentencia, pues solo asi podrá quedar excluida la discrecionalidad y podrá controlarse por los recursos la razonabilidad de la declaración de hechos probados" 31 .

Pero también el propio legislador, si todavía alguna duda cabe, ha exigido que las sentencias, en que se ha apreciado la prueba en conciencia, sean motivadas. Claros son al respecto el tenor del inciso $2^{\circ}$ del art. 14 de la Ley 18.287 que establece procedimiento ante los juzgados de policía local y el art. 456 del Código del Trabajo, ambas disposiciones de igual redacción: "Al apreciar la prueba de acuerdo con las reglas de la sana crítica, el tribunal deberá expresar las razones jurídicas y las simplemente lógicas, científicas o técnicas en cuya virtud les asigne valor o las desestime...”. Igualmente la legislación más reciente como lo son el artículo 32 de la Ley $\mathrm{N}^{\circ} 19.968$ sobre nuevos tribunales de familia y el artículo 297 del nuevo Código Procesal Penal (disposiciones de similar redacción) exigen claramente que las sentencias dictadas en estos juicios -en que se ha

27 Colombo (1981) p. 180.

28 AlCALÁ-Zamora (1934) p. 165.

${ }^{29}$ Cfr. LESSONA (1928) pp. 355 y ss.

30 PAillás (1991) pp. 24, 28, 29.

${ }^{31}$ Montero (1996) p. 343. 
autorizado para fallar de acuerdo a la sana crítica- se fundamenten detalladamente: “...La sentencia deberá hacerse cargo en su fundamentación de toda la prueba rendida, incluso de aquella que hubiere desestimado, indicando en tal caso las razones tenidas en cuenta para hacerlo. La valoración de la prueba en la sentencia requerirá el señalamiento de los medios de prueba mediante los cuales se dieren por acreditados cada uno de los hechos, de modo de contener el razonamiento utilizado para alcanzar las conclusiones a que llegare la sentencia”. En armonía con el art. 297 del C.P.P. el art. 342, denominado "Contenido de la sentencia", expresa que: "la sentencia definitiva contendrá: c) La exposición clara, lógica y completa de cada uno de los hechos y circunstancias que se dieren por probados, fueren ellos favorables o desfavorables al acusado, y de la valoración de los medios de prueba que fundamentaren dichas conclusiones de acuerdo con lo dispuesto en el artículo 297”.

\section{LA PRAXIS QUE SE DEBE SUPERAR}

¿Están los jueces cumpliendo en la práctica con su deber constitucional, legal, moral -e incluso de prestigio como dice un autor- de fundamentar sus sentencias en aquellos casos en que tienen la facultad de apreciar la prueba en conciencia?

$\mathrm{Al}$ parecer hay un consenso generalizado en que lamentablemente ello no es así pues lo que se acostumbra ver en las sentencias es que luego de una simple relación de la prueba rendida -que en la forma aparente de un análisis, es más bien un resumen de ella- seguida de la genérica afirmación "y que habiéndose apreciado la prueba en conciencia” las causas se fallan sin más. Ese es todo el razonamiento que muchas veces se expresa en los textos de los fallos.

A este respecto es lapidaria y gráfica la opinión de Gonzalo Calvo “...la apreciación de la prueba en conciencia (...) se ha transformado desgraciadamente, en su aplicación real en gran parte de los casos, en una mera expresión gramatical, que en el hecho suple el análisis que debe realizarse cuando se establece la existencia de los hechos, produciéndose así un retroceso en lugar de un progreso, si se tiene presente la garantía a que tienen derecho los justiciables de ser juzgados conociendo la fundamentación del fallo manifestada en los motivos que lo determinan en uno u otro sentido" 32 .

No se le puede dar el carácter de fundamentación (incluso faltaría esta) a la enumeración, tipo parte expositiva, del resumen de la actividad probatoria, ya que ello obviamente no es ponderación o valoración. La práctica nos demuestra que los jueces se limitan en sus fallos a expresar, escuetamente, que han apreciado la prueba en conciencia, lo que es inaceptable, pues no existe ninguna disposición que los exima de la fundamentación, sobre todo, si se tienen en cuenta las expresas normas que al permitir fallar según la sana crítica les exige inmediatamente a los jueces la obligación de expresar las razones de sus fallos dictados conformes a dicho sistema de valoración. Piénsese,

32 Calvo (1981) pp. 142-144. 
incluso, que si todo testigo debe dar razón de sus dichos, más aún el juez que administra justicia, está obligado a dar razón de sus decisiones.

Lo anterior se resume en la afirmación "A mayor discrecionalidad, mayor fundamentación" que no es sino una expresión de la más general "A mayor libertad, mayor responsabilidad".

El sistema de la persuasión racional supone en el juez independencia y capacidad mucho mayor que en el sistema de la prueba legal; la obligación de fundar las sentencias es un eficaz correctivo de cuanto se podría encontrar de demasiado arbitrario en él. En este sistema la sentencia no ha de ser un acto de fe, sino un documento de convicción razonada. Parafraseando a Unamuno con esta facultad el juez no debe vencer, sino convencer.

Como dijimos al comienzo de este trabajo muy pronto en Chile la apreciación de la prueba de acuerdo a la sana crítica será la regla general en todo nuestro sistema jurídico por lo que es imperioso desterrar a la brevedad la práctica de escudarse en tan noble herramienta para no fundar o motivar las sentencias.

\section{CONCLUSIÓN}

La sana crítica en nuestro ordenamiento jurídico ha pasado de ser un sistema residual de valoración de la prueba a uno que se ha abierto paso en muchas e importantes materias, y seguramente pasará a ser la regla general cuando se apruebe el nuevo Código Procesal Civil.

Sus elementos esenciales son los principios de la lógica, las máximas de la experiencia, los conocimientos científicamente afianzados y la fundamentación de las decisiones.

La forma en que la sana crítica se está empleando por los tribunales no puede continuar ya que desgraciadamente muchos jueces amparados en este sistema no cumplen con su deber ineludible de fundamentar adecuadamente sus sentencias. Las consecuencias de esta práctica socavan el sistema judicial mismo desde que, entre otros aspectos, no prestigia a los jueces, estos se ven más expuestos a la crítica interesada y fácil de la parte perdedora y, además, muchas veces produce la indefensión de las partes pues estas no sabrán cómo fundamentar sus recursos ante instancias superiores al no conocer los razonamientos del sentenciador.

Fecha de recepción: 1 de marzo 2006 Fecha de aceptación: 3 de abril 2006 


\section{BIBLIOGRAFÍA CITADA}

Alcalá-Zamora y CASTillo, Niceto (1936): "Notas para la reforma de la ley de Enjuiciamiento Civil", Estudios de Derecho Procesal (Madrid).

Alsina, Hugo (1956): Tratado Teórico Práctico de Derecho Procesal Civil y Comercial (Buenos Aires, Ediar S. A. Editores), v. I: 760 pp.

Cabañas García, Juan Carlos (1992): La Valoración de las Pruebas y su Control en el Proceso Civil (Madrid, Editorial Trivium S.A.).

CAlamandreI, Piero (1961): Estudios sobre el proceso civil (Buenos Aires, Editorial Bibliográfica Argentina) 646 pp.

Calvo Castro, Gonzalo (1981): "Sistemas de apreciación de la prueba”, VV.AA. (coord. Dunlop Rudolffi, Sergio) Nuevas Orientaciones de la Prueba (Santiago, Editorial Jurídica de Chile).

CARNELLI, Lorenzo (1946): "Las máximas de experiencia en el proceso de orden dispositivo", Estudios de Derecho Procesal en Honor de Hugo Alsina (Buenos Aires, Ediar S.A.).

Cena Egaña, José Luis (1988): Tratado de la Constitución de 1980 (Santiago, Editorial Jurídica de Chile) 402 pp.

Colombo CAmpbell, Juan (1981): "Sistemas de valoración de la prueba", VV.AA. (coord. Dunlop Rudolffi, Sergio) Nuevas Orientaciones de la Prueba, (Santiago, Editorial Jurídica de Chile).

COMisión PARA la Reforma del Proceso Civil (2005): Propuesta de bases para redactar un Nuevo Código Procesal Civil para la República de Chile (Santiago, Facultad de Derecho de la Universidad de Chile y Ministerio de Justicia de la República de Chile).

COUTURE, Eduardo (1960): Vocabulario Jurídico (Montevideo).

Couture, Eduardo (1966): Fundamentos del Derecho Procesal Civil (Buenos Aires, Ediciones Depalma) 379 pp.

Couture, Eduardo (1979): Estudios de Derecho Procesal Civil (Buenos Aires, Ediciones Depalma) t. II: 478 pp.

Departamento de Derecho Procesal de la Pontificia Universidad Católica DE CHILE (2005): Bases generales para una Reforma Procesal Civil (Santiago).

Devis EChandía, Hernando (1966): Nociones Generales de Derecho Procesal Civil (Madrid, Ediciones Aguilar) 772 pp.

Devis Echandía, Hernando (1972): Teoría General de la Prueba Judicial (Buenos Aires), t. I.

Dunlop RudolfFi, Sergio (coord.) (1981): Nuevas Orientaciones de la Prueba (Santiago, Editorial Jurídica de Chile) 210 pp.

GUZMÁn TAPIA, Juan (1996): La Sentencia (Santiago, Editorial Jurídica de Chile) 123 pp.

JiMÉNEZ CONDE, Fernando (1978): La apreciación de la prueba legal y su impugnación (Salamanca, Ed. Universidad de Salamanca) 365 pp.

Lessona, Carlos (1928): Teoría General de la Prueba en Derecho Civil (traducc. Enrique Aguilera de PAZ, Madrid, Editorial Reus S.A.) v. 1: 601 pp.

Montero Aroca, Juan (1996): La Prueba en el Proceso Civil (Madrid, Editorial Civitas S.A.) $353 \mathrm{pp}$. 
Oberg YÁneZ, Héctor (1985): "Las Máximas de Experiencia”, Revista de Derecho Universidad de Concepción, $\mathrm{N}^{\circ} 178$.

Paillás PeñA, Enrique (1991): Estudios de Derecho Probatorio (Santiago, Editorial Jurídica de Chile) 163 pp.

Peñailillo Arévalo, Daniel (1993): La prueba en materia sustantiva civil. Parte General (Santiago, Editorial Jurídica de Chile) 126 pp.

Pereira Anabalón, Hugo (1992): "Motivación y fundamentación de las sentencias y debido proceso", Gaceta Jurídica, N 142 (Santiago).

RiOSECO ENRÍQUeZ, Emilio (1995): La prueba ante la jurisprudencia (Santiago, Editorial Jurídica de Chile), t. I.

Rodríguez Garcés, Sergio (1993): Derecho Procesal Funcional (Santiago, Ediciones Vitacura Ltda.).

SALAS VIVALDI Julio (1993): "La apreciación de la prueba en conciencia y conforme a las reglas de la sana crítica. Una polémica revivida”, Revista de Derecho Universidad de Concepción, $\mathrm{N}^{\circ} 193$.

STEIN, Friedrich (1988): El conocimiento privado del juez (traducc. de Andrés DE LA Oliva SANTOS, Bogotá, Editorial Temis) 188 pp.

Stoehrel Maes, Carlos (1995): De las disposiciones comunes a todo procedimiento y de los incidentes (Santiago, Editorial Jurídica de Chile) 210 pp.

Vodanovic, Antonio (1994): Derecho de Alimentos, (Santiago, Editorial Jurídica ConoSur) 309 pp.

ZAPATA DíAZ, Hernán (1968): "La conciencia como elemento de la valoración de la prueba", Revista de Derecho y Jurisprudencia, t. 65, primera parte.

\section{JURISPRUDENCIA CITADA}

Budinich con Cerda (1966): Corte Suprema 26 marzo 1966 (Casación Forma y Fondo), Revista de Derecho y Jurisprudencia y Gaceta de los Tribunales, t. 63 (1966), secc. 1a, p. 66.

Cía. Salitrera Anglo Chilena (1933): Corte Suprema 1 agosto 1933 (Queja), Revista de Derecho y Jurisprudencia y Gaceta de los Tribunales, t. 30 (1933), secc. 1ª, pp. 502-503.

Contra Garacino, José (1960): Corte Suprema 1 abril 1960 (Casación de oficio), Revista de Derecho y Jurisprudencia y Gaceta de los Tribunales, t. 57 (1960), secc. 4a, p. 41.

Duque, Wenceslao (1972): Corte Suprema 10 agosto 1972 (Queja), Revista de Derecho y Jurisprudencia y Gaceta de los Tribunales, t. 69 (1972), secc. 1ª, p. 131.

Infante y otros con Jury (1970): Corte Suprema 6 octubre 1970 (Casación Forma y Fondo), Revista de Derecho y Jurisprudencia y Gaceta de los Tribunales, t. 67 (1970), secc. $1^{\text {a }}$, p. 447.

Muñoz con Corte de Apelaciones Valparaiso (1955): Corte Suprema 15 septiembre 1955 (Queja), Revista de Derecho y Jurisprudencia y Gaceta de los Tribunales, t. 52 (1955), secc. $3^{\mathrm{a}}$, p. 41 , cons. $1^{\mathrm{o}}$.

Peretta con Simunovic (1971): Corte Suprema 1 abril 1971 (Casación Fondo y Forma), Revista de Derecho y Jurisprudencia y Gaceta de los Tribunales, t. 68 (1971), secc. 1a, p. 76. 
